\title{
Trends and comparison of female first authorship in high impact medical journals: observational study (1994-2014)
}

\author{
Giovanni Filardo, ${ }^{1}$ Briget da Graca, ${ }^{2}$ Danielle M Sass, ${ }^{1}$ Benjamin D Pollock, ${ }^{1}$ Emma B Smith, ${ }^{3}$ \\ Melissa Ashley-Marie Martinez ${ }^{4}$
}

'Department of Epidemiology, Office of the Chief Quality Officer, Baylor Scott \& White Health, 8080 North Central Expressway, Dallas, TX 75206 , USA

${ }^{2}$ Center for Clinical

Effectiveness, Office of the Chief Quality Officer, Baylor Scott \&

White Health, Dallas

3Yale University, New Haven, CT 06520, USA

4 University of New Mexico School of Medicine,

Albuquerque, NM 87131, USA

Correspondence to: G Filardo giovanfi@baylorhealth.edu

Cite this as: BMJ 2016;352:i847 http://dx.doi.org/10.1136/bmj.i847

Accepted: 27 January 2016

\section{ABSTRACT}

OBJECTIVE

To examine changes in representation of women among first authors of original research published in high impact general medical journals from 1994 to 2014 and investigate differences between journals.

\section{DESIGN}

Observational study.

STUDY SAMPLE

All original research articles published in Annals of Internal Medicine, Archives of Internal Medicine, The $B M J$, JAMA, The Lancet, and the New England Journal of Medicine (NEJM) for one issue every alternate month from February 1994 to June 2014.

\section{MAIN EXPOSURES}

Time and journal of publication.

\section{MAIN OUTCOME MEASURES}

Prevalence of female first authorship and its adjusted association with time of publication and journal, assessed using a multivariable logistic regression model that accounted for number of authors, study type and specialty/topic, continent where the study was conducted, and the interactions between journal and time of publication, study type, and continent. Estimates from this model were used to calculate adjusted odds ratios against the mean across the six

\section{WHAT IS ALREADY KNOWN ON THIS TOPIC}

Two previous studies, limited to US and UK researchers and sampling only one year from each decade, showed increasing female first authorship in high impact medical journals from 1970 to 2004

They showed that women accounted for $29 \%$ of US affiliated and $37 \%$ of UK affiliated first authors in 2004

Other studies report similar changes over time for specialty specific journals No previous studies have compared the representation of women among first authors across high impact general medical journals

\section{WHAT THIS STUDY ADDS}

This study provides an updated, rigorous examination of women's representation among first authors of original research papers in six high impact general medical journals, covering the period 1994-2014

Women made meaningful gains in first authorship, accounting for approximately $37 \%$ of first authors in 2014; however, since around 2009, female first authorship seems to have plateaued and to be in decline in some journals

Compared with the mean across the six journals, first authors were significantly less likely to be women in the New England Journal of Medicine and significantly more likely to be women in The BMJ over the 20 year period examined

These results show that underrepresentation of women among the leaders of high impact original research is a continuing concern

journals, with $95 \%$ confidence intervals and $P$ values to describe the associations of interest.

\section{RESULTS}

The gender of the first author was determined for 3758 of the 3860 articles considered; 1273 (34\%) were women. After adjustment, female first authorship increased significantly from $27 \%$ in 1994 to $37 \%$ in 2014 ( $\mathrm{P}<0.001)$. The NEJM seemed to follow a different pattern, with female first authorship decreasing; it also seemed to decline in recent years in The BMJ but started substantially higher (approximately $40 \%$ ), and The BMJ had the highest total proportion of female first authors. Compared with the mean across all six journals, first authors were significantly less likely to be female in the NEJM (adjusted odds ratio 0.68, 95\% confidence interval 0.53 to 0.89 ) and significantly more likely to be female in The BMJ $(1.30,1.01$ to 1.66) over the study period.

\section{CONCLUSIONS}

The representation of women among first authors of original research in high impact general medical journals was significantly higher in 2014 than 20 years ago, but it has plateaued in recent years and has declined in some journals. These results, along with the significant differences seen between journals, suggest that underrepresentation of research by women in high impact journals is still an important concern. The underlying causes need to be investigated to help to identify practices and strategies to increase women's influence on and contributions to the evidence that will determine future healthcare policies and standards of clinical practice.

\section{Introduction}

Worldwide, women have made substantial gains in participation in the medical profession. Approximately equal numbers of women and men enter and graduate from medical school in the United States and United Kingdom. ${ }^{12}$ In northern and eastern European countries such as Russia, Finland, Hungary, and Serbia, women account for more than $50 \%$ of the active physicians $^{3}$; in the United Kingdom and United States, they represent $47 \%$ and 33\% respectively. ${ }^{45}$ Even in Japan, the nation in the Organisation for Economic Co-operation and Development with the lowest percentage of female physicians, representation doubled between 1986 and 2012. ${ }^{36}$ However, progress in academic medicine continues to lag, with women accounting for less than $30 \%$ of clinical faculty overall and for less than $20 \%$ of those at the highest grade or in leadership positions. ${ }^{7-9}$ Understanding the extent to which this underrepresentation affects high impact research is critical because of the implicit bias it introduces to the research 
agenda, influencing future clinical practice. ${ }^{1011}$ Given the importance of publication for tenure and promotion, ${ }^{12}$ women's publication in high impact journals also provides insights into the degree to which the gender gap can be expected to close.

Two previous studies, one in the United States and one in the United Kingdom, looked at changes in proportions of women versus men among first authors who published original research papers in high impact journals in key specialties from 1970 to 2004, but they were limited to authors with affiliations in those countries and, in the case of the US study, to authors with MD degrees. ${ }^{1314}$ Although the gender gap in their samples narrowed considerably during the study period, women still accounted for only $29.3 \%$ and $36.7 \%$ of US and UK affiliated first authors in 2004. ${ }^{1314}$ Similar results have been reported for journals focusing on specific specialties. ${ }^{15-19}$ Although several of these previous studies noted substantial differences in the prevalence of female first authorship between journals, ${ }^{1316-1820}$ only one study, limited to gastroenterology journals and looking only at US affiliated authors with MD degrees, ${ }^{18}$ conducted a formal comparison.

Here, we examine the prevalence of female first authorship of original research, irrespective of degrees, affiliations, and country where the study was conducted, in six high impact general medical journals, looking at both changes over time and differences between journals. Identifying differences provides the opportunity to discern practices and strategies to help to increase women's representation among the researchers most likely to inform future studies and to influence healthcare policies and standards of practice, remedying the bias in these areas implicit in women's current underrepresentation.

\section{Methods}

We assessed the prevalence of female first authorship of original research articles published in high impact general and internal medicine journals for the period 1994 to 2014. We examined changes over time as well as differences between journals.

\section{Data collection}

Inclusion and exclusion criteria

We selected the six journals with the highest 2012 Journal Citation Reports impact factors in the category "Medicine, general \& internal" for which the publication format enabled us to determine, from either the table of contents or the full text of the article, the number of authors, their first and last names, the country where the study was conducted, and the article type, specialty/topic, and study design. We collected data for original research articles (including meta-analyses) published in these six journals from February 1994 to June 2014.

The six journals were Annals of Internal Medicine (Annals), Archives of Internal Medicine/JAMA-Internal Medicine (Archives), The BMJ, JAMA, The Lancet, and the New England Journal of Medicine (NEJM). To ensure a representative sample of all the original research articles published during the study period and to ensure that the sample was robust to short term variations in the prevalence of women among first authors, we collected data for issues published in even numbered months (February, April, June, August, October, December) for each year; if more than one issue was published per month, we restricted data collection to the second issue of each of those months. In the event that the second issue did not include any original research publications, we collected data from the first issue published that month.

\section{Variables of interest}

For each original research article, we collected data on time of publication (year and month), journal, gender of the first author (female, male, unknown), total number of authors, study type (experimental or non-experimental, defined below), specialty/topic (grouped into general medicine, cardiovascular disease/surgery, infectious disease, oncology, HIV/AIDS, other), and country where the study was conducted (grouped into continents).

We determined the gender of the first author by inspection of the first name. If an author's gender was unclear from their name, we used institutional websites, social media accounts that listed their publications (such as LinkedIn), and internet search engines (such as Google) to find photographs and/or biographical paragraphs. We marked any first authors whose genders were not clearly identifiable after we had exhausted these sources as "unknown" and excluded the article from the analysis.

We defined the total number of authors as the count of the named authors. If a group author (for example, "The EPILOG Investigators"21) was listed at the end of a list of named authors, we did not include the group in the total count; however, if a group author was listed without any preceding named authors, and the names of the members of that group or its writing committee were detailed elsewhere in the article (for example, acknowledgments section), we tallied those names for the total author count.

We classified each original research article in our sample as either experimental (randomized controlled trials, non-randomized experimental studies, and meta-analyses) or non-experimental (descriptive, cohort, case-control, and cross sectional studies).

\section{Data quality and cross check}

Three trained abstractors used a standardized data collection tool to collect data, with all abstractors collecting data for all years but alternating months (so that one collected data for the February, June, and October issues and another for the April, August, and December issues) for journals shared between abstractors. Cross checks to assess the quality and reliability of data were performed, with abstractors duplicating each other's data collection for one month in each year for the NEJM and Lancet articles $(n=153)$. This showed a very low rate of discrepancies needing correction in gender of the first author (2\%). Other variables were reviewed for all 
articles, and discrepancies were resolved through discussion between the abstractors, with other members of the study team (GF and DMS) resolving disputes when they could not reach resolution.

\section{Statistical analysis}

We tabulated percentages of female first authors, study types, specialties/topics, and continents where the studies were conducted, as well as the number of countries in which the published research was conducted and the mean number of authors per article, by time of publication (five year intervals).

We used a logistic regression model to model the association between gender and time of publication and between gender and journal. This model included the following independent variables: journal; time of publication (incremental publication month from February 1994 (month 1) to June 2014 (month 245) -to avoid assuming a linear association of time of publication with the outcome of interest and to avoid the bias inherent with categorization, this variable was modeled as a continuous covariate with a five knot restricted cubic spline ${ }^{2223}$ ); total number of listed authors-also modeled using restricted cubic splines ${ }^{22} 23$; study type (experimental versus non-experimental); continent where the study was conducted; specialty/topic (general medicine, cardiovascular disease/surgery, infectious disease, oncology, HIV/AIDS, other); and interaction terms between journal and time of publication, journal and study type, and journal and continent where the study was conducted. As women remain underrepresented in the higher ranks of academic medicine, ${ }^{7}$ the adjustment for total number of listed authors and study type accounted for the possibility that they might be less likely to lead a large research team or to have been funded for the large randomized controlled clinical trials that some of these high impact journals might preferentially publish. We further adjusted our analysis for specialty/topic and continent where the research was conducted to account for possible differences between the journals in these areas, as representation of women varies across specialties and countries. ${ }^{351024}$

We used estimates from this model to calculate adjusted odds ratios (using the mean of female first authorship across the six included journals over the study period as the reference group), 95\% confidence intervals, and $\mathrm{P}$ values to describe the associations of interest. We also generated adjusted plots of the association between time of publication and first author's gender stratified by journal. We used SAS 9.4 for all analyses.

\section{Patient involvement}

Patient involvement was not applicable, as this study solely examined questions about the representation of women among the first authors of high impact published original research. Therefore, no patients were involved in setting the research question or the outcome measures, nor were they involved in the design and implementation of the study, and there are no plans to involve patients in dissemination.

\section{Results}

We collected data for 3860 articles. Of these, we could not determine the gender of the first author for 102 (3\%) (range among journals 14/1244 (1\%) (Archives) to 33/531 $(6 \%)(B M J))$. We excluded these, leaving 3758 articles in the final analyses. In total, across the full 20 year period and all six journals, 1273 (34\%) articles had female first authors, and an approximately 10 percentage point increase in female first authorship of original research articles occurred (table 1).

Table 1 shows the percentages of female first authors of original research articles, overall and by time of publication (five year intervals) for each journal, as well as change from baseline. The $B M J$ had the highest unadjusted total proportion of female first authors (193/498; $39 \%)$ and the NEJM the lowest (126/535; 24\%). Whereas most journals showed increasing female first authorship over time, the NEJM seemed to follow a different pattern, ending with a lower proportion in 2009-14 than it started with in 1994-99. The BMJ also saw a decrease in the representation of women in recent years, and in 2009-14 JAMA, Archives, and Annals overtook it in the prevalence of female first authorship.

Table 1 also shows changes over time in the continent where published studies were conducted (as well as the total number of countries represented across the published studies), the specialty/topic covered by the published studies, and the mean number of authors per article. The published research captured in our study sample originated from 50 countries, predominantly in North America and Europe. We saw an increase over time in the proportion of studies conducted on multiple continents, but studies conducted only in Africa, Asia, Australia, or South America were relatively underrepresented (171/3758; 5\%).With respect to specialty/topic, general medicine was the most common, followed by cardiovascular disease/surgery. Both the infectious disease and HIV/AIDS topic categories showed small declines over the study period, and oncology and other increased to similar degrees.

Table 2 shows the prevalence of female first authorship over time by study type (experimental and non-experimental), as well as change from baseline. The BMJ had the highest unadjusted percentage of female first authors in both types of study (138/346 (40\%) non-experimental; 55/152 (36\%) experimental), and the NEJM had the lowest (77/267 (29\%) non-experimental; 49/268 (18\%) experimental). Table 2 shows substantial increases in female first authorship during the study period across both study types for four of the six included journals. The largest gains from 1994-98 to 2009-14, all of at least 20 percentage points, were in non-experimental studies published in Annals and experimental studies published in JAMA, Archives, and The Lancet.

We saw similar results after adjustment, as shown in figure 1. Overall, the adjusted probability of an article having a female first author increased significantly between February 1994 and June $2014(\mathrm{P}<0.001)$, going from approximately $27 \%$ (The BMJ was the anomaly, starting at approximately $40 \%$ ) to approximately $37 \%$. 
Table 1 | Percentages of female first authors and study characteristics (countries/continents where conducted, specialties/topics covered, and number of listed authors) by year of publication and journal. Values are numbers (percentages) unless stated otherwise

\begin{tabular}{|c|c|c|c|c|c|c|}
\hline & $1994^{*}-98$ & $1999-2003$ & 2004-08 & $2009-14 t$ & Total & $\begin{array}{l}\text { Change from } 1994-98 \text { to } \\
2009-14 \text { (percentage points) }\end{array}$ \\
\hline \multicolumn{7}{|l|}{ Female first authorship } \\
\hline Annals & 38/151 (25) & 42/113(37) & $35 / 125(28)$ & $65 / 144(45)$ & 180/533 (34) & 20 \\
\hline Archives & $85 / 288(30)$ & 112/338 (33) & $146 / 363(40)$ & $101 / 241(42)$ & 444/1230 (36) & 12 \\
\hline BMJ & 50/141 (36) & $54 / 128(42)$ & $37 / 85(44)$ & $52 / 144(36)$ & 193/498 (39) & 1 \\
\hline JAMA & 36/123 (29) & 46/133(35) & $51 / 121(42)$ & $52 / 117(44)$ & 185/494 (37) & 15 \\
\hline Lancet & $30 / 126(24)$ & $37 / 125(30)$ & $38 / 102(37)$ & 40/115 (35) & $145 / 468(31)$ & 11 \\
\hline NEJM & $35 / 147(24)$ & $32 / 139(23)$ & $32 / 115(28)$ & $27 / 134(20)$ & $126 / 535(24)$ & -4 \\
\hline All & $274 / 976(28)$ & $323 / 976$ (33) & 339/911 (37) & $337 / 895(38)$ & $1273 / 3758(34)$ & 10 \\
\hline Study characteristics & $(n=976)$ & $(n=976)$ & $(n=911)$ & $(n=895)$ & $(n=3758)$ & \\
\hline \multicolumn{7}{|l|}{ Geographic origin: } \\
\hline North America & $572(59)$ & $531(54)$ & $481(53)$ & $450(50)$ & $2034(54)$ & -9 \\
\hline South America & $0(0)$ & $2(<1)$ & $0(0)$ & $1(<1)$ & $3(<1)$ & $<1$ \\
\hline Europe & $258(26)$ & $295(30)$ & $214(23)$ & $204(23)$ & $971(26)$ & -3 \\
\hline Africa & $7(<1)$ & $2(<1)$ & $2(<1)$ & $4(<1)$ & $15(<1)$ & 0 \\
\hline Asia & $28(3)$ & $21(2)$ & $22(2)$ & $23(3)$ & $94(3)$ & 0 \\
\hline Australia & $17(2)$ & $15(2)$ & $16(2)$ & $11(1)$ & $59(2)$ & -1 \\
\hline Multiple continents & $94(10)$ & $110(11)$ & $176(19)$ & $202(23)$ & $582(15)$ & 13 \\
\hline Total No of countries & 33 & 33 & 27 & 37 & 50 & 0 \\
\hline \multicolumn{7}{|l|}{ Specialty/topic: } \\
\hline General medicine & $396(41)$ & $406(42)$ & $391(43)$ & $365(41)$ & $1558(41)$ & 0 \\
\hline Cardiovascular disease/surgery & $253(26)$ & $298(31)$ & $264(29)$ & $238(27)$ & $1053(28)$ & 1 \\
\hline Infectious disease & $156(16)$ & $121(12)$ & $108(12)$ & $108(12)$ & $493(13)$ & -4 \\
\hline Oncology & $77(8)$ & $70(7)$ & $74(8)$ & $108(12)$ & $329(9)$ & 4 \\
\hline HIV/AIDS & $60(6)$ & $30(3)$ & $24(3)$ & $18(2)$ & $132(4)$ & -4 \\
\hline Other & $34(3)$ & $51(5)$ & $50(5)$ & $58(6)$ & $193(5)$ & 3 \\
\hline Mean (SD) total No of listed authors & $6.0(3.7)$ & $6.3(3.7)$ & $8.4(5.8)$ & $9.9(6.9)$ & $7.6(5.4)$ & - \\
\hline
\end{tabular}

Table 2 | Percentages of female first authors and change from baseline, by year of publication, journal, and study type. Values are percentages (numbers) unless stated otherwise

\begin{tabular}{|c|c|c|c|c|c|c|}
\hline & $1994^{*}-98$ & 1999-2003 & 2004-08 & $2009-14 \dagger$ & Total & $\begin{array}{l}\text { Change from 1994-98 to 2009-14 } \\
\text { (percentage points) }\end{array}$ \\
\hline \multicolumn{7}{|c|}{ Non-experimental studies } \\
\hline Annals & $26(23 / 90)$ & $40(33 / 83)$ & $32(19 / 60)$ & $51(36 / 71)$ & $37(111 / 304)$ & 25 \\
\hline Archives & $33(75 / 224)$ & $37(93 / 251)$ & $40(119 / 300)$ & $42(76 / 183)$ & $38(363 / 958)$ & 8 \\
\hline BMJ & $35(40 / 114)$ & $49(49 / 101)$ & $40(19 / 47)$ & $36(30 / 84)$ & $40(138 / 346)$ & 1 \\
\hline JAMA & $33(34 / 103)$ & $37(34 / 92)$ & $45(38 / 84)$ & $46(37 / 81)$ & $40(143 / 360)$ & 13 \\
\hline Lancet & $27(25 / 93)$ & $39(29 / 75)$ & $38(21 / 55)$ & $31(14 / 45)$ & $33(89 / 268)$ & 4 \\
\hline NEJM & $28(25 / 88)$ & $28(22 / 79)$ & $38(15 / 40)$ & $25(15 / 60)$ & $29(77 / 267)$ & -3 \\
\hline All & $31(222 / 712)$ & $38(260 / 681)$ & $39(231 / 586)$ & $40(208 / 524)$ & $37(921 / 2503)$ & 9 \\
\hline \multicolumn{7}{|c|}{ Experimental studies } \\
\hline Annals & $25(15 / 61)$ & $30(9 / 30)$ & $25(16 / 65)$ & $40(29 / 73)$ & $30(69 / 229)$ & 15 \\
\hline Archives & $16(10 / 64)$ & $22(19 / 87)$ & $43(27 / 63)$ & $43(25 / 58)$ & $30(81 / 272)$ & 28 \\
\hline BMJ & $37(10 / 27)$ & $19(5 / 27)$ & $47(18 / 38)$ & $37(22 / 60)$ & $36(55 / 152)$ & 0 \\
\hline JAMA & $10(2 / 20)$ & $29(12 / 41)$ & $35(13 / 37)$ & $42(15 / 36)$ & $31(42 / 134)$ & 32 \\
\hline Lancet & $15(5 / 33)$ & $16(8 / 50)$ & $36(17 / 47)$ & $37(26 / 70)$ & $28(56 / 200)$ & 22 \\
\hline NEJM & $17(10 / 59)$ & $17(10 / 60)$ & $23(17 / 75)$ & $16(12 / 74)$ & $18(49 / 268)$ & -1 \\
\hline All & $20(52 / 264)$ & $21(63 / 295)$ & $33(108 / 325)$ & $35(129 / 371)$ & $28(352 / 1255)$ & 15 \\
\hline
\end{tabular}

Annals, Archives, JAMA, and The Lancet all followed a similar pattern, with the greatest increases happening from approximately 2000 to 2008. The NEJM and The $B M J$, however, showed small decreases over the first five years, followed by increases back to their approximate starting points around 2007-08, before once again declining (fig 1). Figure 2 shows the adjusted odds ratios for female first authorship, comparing each journal with the mean across the six journals: first authors were significantly less likely to be female in the NEJM compared with the overall mean (adjusted odds ratio $0.68,95 \%$ confidence interval 0.53 to 0.89 ), whereas 


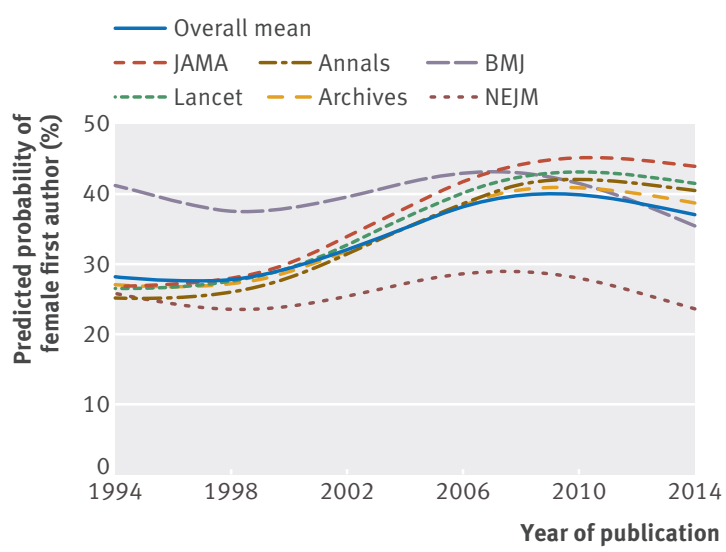

Fig 1 | Adjusted association between female first author and time of publication by journal (February 1994 to June 2014). Model included the following independent variables: journal, time of publication, total number of listed authors, study type (experimental $v$ non-experimental), continent where study was conducted, specialty/topic (general medicine, cardiovascular disease/surgery, infectious disease, oncology, HIV/AIDS, other) of study, and interaction terms between journal and time of publication, journal and study type, and journal and continent where study was conducted. Adjusted P value for association between time of publication and female first authorship was $<0.001$. Annals $=$ Annals of Internal Medicine; Archives=Archives of Internal Medicine/JAMA-Internal Medicine; NEJM=New England Journal of Medicine

first authors in The BMJ were significantly more likely to be female (1.30, 1.01 to 1.66$)$.

\section{Discussion}

Our results show further narrowing of the gender gap in first authorship in high impact medical journals that has been previously reported, ${ }^{13}{ }^{14}$ but also that, since around 2009, female first authorship has either plateaued or declined in all the journals examined. In

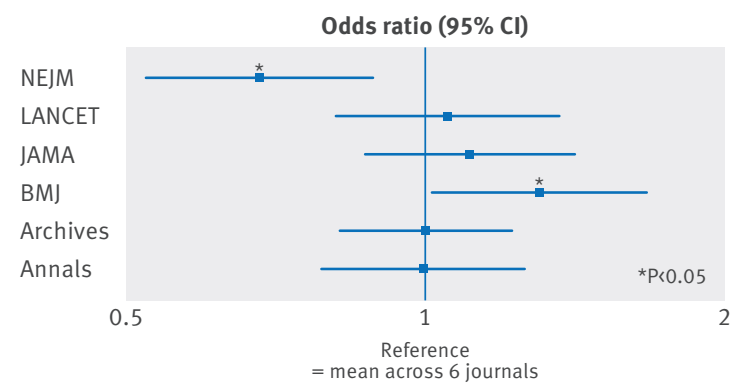

Fig 2 Adjusted odds ratios (reference=mean across six journals) for female first authorship by journal. Model included the following independent variables: journal, time of publication, total number of listed authors, study type (experimental $v$ non-experimental), continent where study was conducted, specialty/topic (general medicine, cardiovascular disease/surgery, infectious disease, oncology, HIV/AIDS, other) of study, and interaction terms between journal and time of publication, journal and study type, and journal and continent where study was conducted. Annals=Annals of Internal Medicine; Archives=Archives of Internal Medicine/JAMA-Internal Medicine; NEJM=New England Journal of Medicine total, in the six journals we examined, the representation of women among the first authors of original research increased from $28 \%$ in $1994-98$ to $38 \%$ in 2009 14. This gain persisted when we examined experimental and non-experimental studies separately but was not consistent across journals. The NEJM and The BMJ were the anomalies: female first authorship increased in neither to the extent seen in the other journals and, in recent years, it declined. However, The BMJ started with a substantially greater proportion of female first authors than the other five journals in 1994-98 and had the highest total proportion over the 20 year period. After adjustment for study type, specialty/topic, and continent, as well as for total number of authors, our data confirmed the significant gain (from 27\% in 1994 to $37 \%$ in 2014; $\mathrm{P}<0.001$ ) (fig 1) described above, and showed that, compared with the mean across the six journals, first authors were significantly more likely to be female in The BMJ and significantly less likely to be female in the NEJM (figures 1 and 2).

\section{Comparison with previous studies}

Ours is the first formal comparison of female first authorship between high impact general medical journals. Previous studies examining the representation of women did not formally test the differences between the journals included in their samples. ${ }^{1314}$ One previous study, limited to major gastroenterology journals and looking only at US affiliated authors with MD degrees, did test for and find significant differences in female first authorship between journals, after adjusting for year of publication, research subject, and MD versus MD-PhD degree. ${ }^{18}$ The authors suggested that these differences might, at least in part, reflect the practice choices of female gastroenterologists, with few of them subspecializing in areas on which certain journals focused. ${ }^{18}$

\section{Possible explanations for observed results}

Multiple factors could potentially underlie the differences in female first authorship we observed between the high impact general medical journals in our sample. Our adjusted analysis accounted for the possibility that these journals may vary in their priorities for publishing different types of studies (for example, prioritizing large randomized controlled trials, for which women, who receive fewer and smaller research grants from both public and industry sources, ${ }^{25-28}$ may be less likely to serve as the principal investigator and/or first author, could affect a journal's representation of women among first authors) or studies covering particular specialties/ topics or conducted in particular geographic regions (which could affect female first authorship, as the representation of women varies widely across both specialties and countries ${ }^{351024}$ ). Our results therefore indicate that that these factors do not explain the differences observed in our study. Other possibilities, for which we could not account, include differences between journals in how submitted manuscripts are reviewed and how decisions about acceptance or rejection are made, although our examination of the descriptions of the 
review procedures the journals included in our study provide in their online information for authors did not find obvious differences in the use of processes such as double blind review or in who holds the final decision making power regarding acceptance, ${ }^{29}{ }^{34}$ which have been suggested as affecting representation of female authors. ${ }^{35}{ }_{37}$ It is, however, intriguing to note that our data show that the four included journals with female editors-in-chief for all or most of the 2009-14 period had the highest unadjusted rates of female first authorship during these years (45\% Annals, 44\% JAMA, 42\% Archives, and 36\% BMJ), ${ }^{38-41}$ whereas the remaining two journals had considerably lower rates (20\% NEJM, 35\% Lancet). ${ }^{4243}$ This observation warrants further investigation-it may be that the gender of the journal's editorin-chief affects factors such as the likelihood that women will submit their articles to the journal or the prioritization of study types and topics in which female clinical researchers are more likely to engage.

Composition of editorial boards (in which women remain vastly underrepresented ${ }^{44}$ ) could also indirectly affect women's success in publishing their research in a particular journal: previous research has shown both that male editors are more likely to assign manuscripts to male reviewers and that reviewers are more likely to recommend rejection when they are of the opposite sex to the manuscript's author. ${ }^{45}$ Investigating this possible explanation would require detailed data from the journals regarding submissions, editor and reviewer assignments, and resulting recommendations/decisions.

The possibility that female authors may be more likely to submit their research to some journals than others is another factor that might underlie the difference between journals. Similar to the pattern that has been found in grant applications for public research funds, whereby women tend to have similar success rates but lower application rates, ${ }^{25} 262846$ female first authors may be less likely to submit their manuscripts to the top ranked journals. Investigating this possibility would require access to the data on journal submissions as well as publications to investigate. Both JAMA and the Middle European Journal of Medicine have studied acceptance rates with their submission data, with neither finding significant differences based on authors' gender, ${ }^{45} 47$ but to our knowledge no studies of submission patterns between journals or over time have been done.

With respect to the observation that female first authorship has plateaued or declined since 2009 at a level below women's representation in the medical community, this may well be attributable to the subtle and unconscious gender bias that persists in the scientific community: Studies show that both men and women rate identical scientific abstracts or applications for a laboratory manager's position as of higher quality when these are submitted under a male rather than female name, ${ }^{4849}$ link science words more quickly with male than female names, ${ }^{36}$ and give harsher reviews to female authored submissions. ${ }^{50}$ Such bias disadvantages women at all stages in the research process-from career choice and progression, to funding applications, to publication. Whether this manifests through fewer women submitting applications or manuscripts or through women being less successful when they do submit, our results show that a fundamental shift in how female researchers are viewed-and how they view their own role in the scientific community-is still needed to ensure that their contributions to medical science have an equal opportunity to be heard.

\section{Strengths and limitations of study}

Our study used methods to determine first authors' gender similar to those reported previously in investigations examining gender and authorship, ${ }^{13-15} 185152$ but some misclassification may have occurred. The low rate of discrepancy between the abstractors (2\%) provides reassurance that such misclassification should be rare; more importantly, it would be non-differential. Likewise, any differences in how research teams designated first authorship on their articles should be non-differential across journals. Our results are based on a large sample of original research articles reporting on studies conducted in 50 countries and published over a 20 year study period, gathered through the uniform application across journals and years of a sampling method that selected one issue every other month for each journal. This method was designed to ensure a sample that is both representative of all the original research articles published in the included journals and robust to short term variations (as short as every two months) in the percentages of female first authors. As such, our results provide a more accurate and comprehensive picture of the changes over time than would be afforded by a sample composed, for example, of only the original research articles with US or UK affiliated authors published in the included journals in a single year per decade. ${ }^{1314}$ Furthermore, we adjusted for study type, specialty/ topic, and continent, as well as for number of authors to account for the possibility that, even within the defined group of high impact, general medical, peer reviewed journals, differences might exist with respect to the type, size, and source of study that is prioritized for publication.

\section{Conclusion}

Overall, our results confirm that the representation of women among first authors of original research published in high impact general medical journals significantly increased over the past 20 years; we have also shown, however, that it seems to have now plateaued and to be in decline in some journals. Our findings further show significant differences between journals in the likelihood of the first author of an original research article being female. Taken together, these findings suggest that underrepresentation of women among the leaders of high impact original research is a continuing concern. Our results are important to the medical community, as the differences between journals provide the basis for identifying practices and strategies that could increase women's representation among the researchers providing the evidence that will drive future healthcare policies and standards of care. This is 
critical to ensuring that women's contributions to the medical research agenda and future clinical practice are not lost, eliminating the current bias implicit in their underrepresentation in clinical academia and among the first authors of original research articles in high impact journals.

Contributors: GF was involved in the study concept and design, data analysis and interpretation, and drafting the manuscript. BdG did the literature search and was involved in the study design, data interpretation, and drafting the manuscript. DMS was involved in data collection and management and in revising the manuscript. BDP was involved in data collection and analysis, generating figures and tables, and drafting the manuscript. EBS and MAM were involved in data collection and revising the manuscript. GF is the guarantor.

Funding: This work was funded in part by the Bradley Family Endowment to the Baylor Health Care System Foundation. The funder played no role in this study, and the research team operated independently.

Competing interests: All authors have completed the ICMJE uniform disclosure form at www.icmje.org/coi_disclosure.pdf and declare: all authors had financial support from Bradley Family Endowment to the Baylor Health Care System Foundation for the submitted work; no financial relationships with any organizations that might have an interest in the submitted work in the previous three years; no other relationships or activities that could appear to have influenced the submitted work.

Ethical approval: Not needed.

Transparency declaration: The lead author (the manuscript's guarantor) affirms that this manuscript is an honest, accurate, and transparent account of the study being reported; that no important aspects of the study have been omitted; and that any discrepancies from the study as planned (and, if relevant, registered) have been explained.

Data sharing: The study dataset is available from the corresponding author on request.

This is an Open Access article distributed in accordance with the Creative Commons Attribution Non Commercial (CC BY-NC 3.0) license, which permits others to distribute, remix, adapt, build upon this work non-commercially, and license their derivative works on different terms, provided the original work is properly cited and the use is noncommercial. See: http://creativecommons.org/licenses/by-nc/3.0/.

1 Association of American Medical Colleges. The state of women in academic medicine: the pipeline and pathways to leadership, 2013-2014. Table 1: Medical students, selected years, 1965-2013. https://www.aamc.org/download/411782/ data/2014_table1.pdf.

2 Centre for Workforce Intelligence. Shape of the medical workforce: starting the debate on the future consultant workforce. 2012. http://www. cfwi.org.uk/publications/leaders-report-shape-of-the-medical-workforce.

3 Ramakrishnan A, Sambuco D, Jagsi R. Women's participation in the medical profession: insights from experiences in Japan, Scandinavia, Russia, and Eastern Europe. J Womens Health (Larchmt) 2014;23:92734. doi:10.1089/jwh.2014.4736

4 British Medical Association. 2014 UK medical workforce briefing. BMA, 2015 (available at http://www.bma.org.uk/-/media/files/ pdfs/workingforchange/policyandlobbying/ ukmedicalworkforcebriefingmay2015final.pdf).

5 Center for Workforce Studies. Physician specialty data book Association of American Medical Colleges, 2014 (available at https:// members.aamc.org/eweb/upload/14-086\%20Specialty\%20 Databook\%202014 711.pdf).

6 Okoshi K, Nomura K, Fukami K, et al. Gender inequality in career advancement for females in Japanese academic surgery. Tohoku J Exp Med 2014;234:221-7. doi:10.1620/tjem.234.221.

7 Association of American Medical Colleges. The state of women in academic medicine: the pipeline and pathways to leadership 2013-2014. https://www.aamc.org/members/gwims/statistics/.

8 Fitzpatrick S. A survey of staffing levels of medical clinical academics in UK medical schools as at 31 July 2014: a report by the Medical Schools Council. Medical Schools Council, 2015 (available at http:// www.medschools.ac.uk/SiteCollectionDocuments/MSC-survey-2015web.pdf).

9 European Commission. She figures 2012: gender in research and innovation. European Union, 2013 (available at http://ec.europa.eu/ research/science-society/document library/pdf_06/ she-figures-2012_en.pdf).

10 Penny M, Jeffries R, Grant J, Davies SC. Women and academic medicine: a review of the evidence on female representation. J $R$ Soc Med 2014:107:259-63. doi:10.1177/0141076814528893.
11 Royal Society of Medicine. Women under-represented in academic medicine. 2014. https://www.rsm.ac.uk/about-us/mediainformation/2014-media-releases/women-under-represented-inacademic-medicine.aspx

12 Reed DA, Enders F, Lindor R, McClees M, Lindor KD. Gender differences in academic productivity and leadership appointments of physicians throughout academic careers. Acad Med 2011;86:43-7. doi:10.1097/ACM.0b013e3181ff9ff2.

13 Jagsi R, Guancial EA, Worobey CC, et al. The "gender gap" in authorship of academic medical literature--a 35-year perspective. $N$ Engl J Med 2006;355:281-7. doi:10.1056/NEJMsa053910.

14 Sidhu R, Rajashekhar P, Lavin VL, et al. The gender imbalance in academic medicine: a study of female authorship in the United Kingdom. J R Soc Med 2009;102:337-42. doi:10.1258/ jrsm.2009.080378

15 Bergeron JL, Wilken R, Miller ME, Shapiro NL, Bhattacharyya N. Measurable progress in female authorship in otolaryngology. Otolaryngol Head Neck Surg 2012;147:40-3. doi:10.1177/0194599812438171.

16 Feramisco JD, Leitenberger JJ, Redfern SI, Bian A, Xie XJ, Resneck JS Jr. A gender gap in the dermatology literature? Cross-sectional analysis of manuscript authorship trends in dermatology journals during 3 decades. I Am Acad Dermatol 2009;60:63-9. doi:10.1016/j. jaad.2008.06.044.

17 Kurichi JE, Kelz RR, Sonnad SS. Women authors of surgical research. Arch Surg 2005;140:1074-7. doi:10.1001/ archsurg.140.11.1074

18 Long MT, Leszczynski A, Thompson KD, Wasan SK, Calderwood AH. Female authorship in major academic gastroenterology journals: a look over 20 years. Gastrointest Endosc 2015;81:1440-1447.e3. doi:10.1016/j.gie.2015.01.032.

19 Amering M, Schrank B, Sibitz I. The gender gap in high-impact psychiatry journals. Acad Med 2011;86:946-52. doi:10.1097/ ACM.Ob013e3182222887.

20 Schrager S, Bouwkamp C, Mundt M. Gender and first authorship of papers in family medicine journals 2006--2008. Fam Med 2011;43:155-9.

21 EPILOG Investigators. Platelet glycoprotein IIb/IIla receptor blockade and low-dose heparin during percutaneous coronary revascularization. N Engl/ Med 1997;336:1689-96. doi:10.1056/ NEIM199706123362401.

22 Harrell FE Jr. Regression modeling strategies: with application to linear models, logistic regression, and survival analysis. Springer-Verlag, 2001.doi:10.1007/978-1-4757-3462-1.

23 Filardo G, Hamilton C, Hamman B, Ng HK, Grayburn P. Categorizing $\mathrm{BMI}$ may lead to biased results in studies investigating in-hospital mortality after isolated CABG. J Clin Epidemiol 2007;60:1132-9. doi:10.1016/j.jclinepi.2007.01.008

24 General Medical Council. The state of medical education and practice in the UK report: 2014. 2014. http://www.gmc-uk.org/ publications/25452.asp.

25 Pohlhaus JR, Jiang H, Wagner RM, Schaffer WT, Pinn VW. Sex differences in application, success, and funding rates for $\mathrm{NIH}$ extramural programs. Acad Med 2011;86:759-67. doi:10.1097/ ACM.0b013e31821836ff.

26 Ranga M, Gupta N, Etzkowitz H. Gender effects in research funding. Deutsche Forschungsgemeinschaft, 2012 (available at http://www. dfg.de/download/pdf/dfg_im_profil/geschaeftsstelle/publikationen/ studien/studie_gender_effects.pdf)

27 Rose SL, Sanghani RM, Schmidt C, Karafa MT, Kodish E, Chisolm GM. Gender differences in physicians' financial ties to industry: a study o national disclosure data. PLoS One 2015;10:e0129197. doi:10.1371/ journal.pone.0129197.

28 Waisbren SE, Bowles H, Hasan T, et al. Gender differences in research grant applications and funding outcomes for medical school faculty. J Womens Health (Larchmt) 2008;17:207-14. doi:10.1089/ jwh.2007.0412.

29 JAMA Internal Medicine. JAMA Internal Medicine instructions for authors. http://archinte.jamanetwork.com/public/ instructionsForAuthors.aspx\#SecEditorialReviewandPublication.

30 JAMA. JAMA instructions for authors. http://jama.jamanetwork.com/ public/instructionsforauthors.aspx\#EditorialReviewandPublication.

31 Campion EW, Curfman GD, Drazen JM. Tracking the peer-review process. N Engl J Med 2000;343:1485-6. doi:10.1056/NEJM200011163432009.

32 How The Lancet handles your paper. http://www.thelancet.com/ lancet/information-for-authors/how-the-lancet-handles-your-paper.

33 Annals of Internal Medicine. Information for authors. http://annals.org/ public/authorsinfo.aspx\#internal-review-by-editors-and-peer-review.

34 The BMJ. Resources for authors. http://www.bmj.com/about-bmj/ resources-authors.

35 Budden AE, Tregenza T, Aarssen LW, Koricheva J, Leimu R, Lortie CJ. Double-blind review favours increased representation of female authors. Trends Ecol Evol 2008;23:4-6. doi:10.1016/j.tree.2007.07.008.

36 Kaatz A, Gutierrez B, Carnes M. Threats to objectivity in peer review: the case of gender. Trends Pharmacol Sci 2014;35:371-3. doi:10.1016/j.tips.2014.06.005. 
37 Tregenza T. Gender bias in the refereeing process? Trends Ecol Evol 2002;17:349-50doi:10.1016/S0169-5347(02)02545-4.

38 JAMA. Masthead. 2015. http://jama.jamanetwork.com/article. aspx?articleid $=2247150$

39 The BMJ. Fiona Godlee. http://www.bmj.com/about-bmj/ editorial-staff/fiona-godlee.

40 Annals of Internal Medicine. About Annals of Internal Medicine. http:// annals.org/public/about.aspx.

41 Redberg RF. The beginning of a new era for the Archives and the nation. Arch Intern Med 2009;169:828. doi:10.1001/ archinternmed.2009.131.

42 The Lancet. About The Lancet medical journal. http://www.thelancet. com/lancet/about.

43 New England Journal of Medicine. The NEJM editor-in-chief. http:// www.nejm.org/page/media-center/editor-in-chief

44 Amrein K, Langmann A, Fahrleitner-Pammer A, Pieber TR, ZollnerSchwetz I. Women underrepresented on editorial boards of 60 major medical journals. Gend Med 2011;8:378-87. doi:10.1016/j. genm.2011.10.007.

45 Gilbert JR, Williams ES, Lundberg GD. Is there gender bias in JAMA's peer review process?JAMA 1994;272:139-42. doi:10.1001/ jama.1994.03520020065018.
46 Jump P. Female success rate dips to 10 per cent in latest ERC grant round. 2015. https://www.timeshighereducation.co.uk/news/ female-success-rate-dips-10-cent-latest-erc-grant-round.

47 Heckenberg A, Druml C. Gender aspects in medical publication - the Wiener klinische Wochenschrift. Wien Klin Wochenschr 2010;122:141-5. doi:10.1007/s00508-010-1302-8.

48 Moss-Racusin CA, Dovidio JF, Brescoll VL, Graham MJ, Handelsman J. Science faculty's subtle gender biases favor male students. Proc Natl Acad Sci U SA 2012;109:16474-9. doi:10.1073/pnas.1211286109.

49 Ceci S), Williams WM, Barnett SM. Women's underrepresentation in science: sociocultural and biological considerations. Psychol Bull 2009;135:218-61. doi:10.1037/a0014412.

50 Broder IE. Review of NSF economics proposals: gender and institutional patterns. Am Econ Rev 1993;83:964-70.

51 Dotson B. Women as authors in the pharmacy literature: 1989-2009. Am J Health Syst Pharm 2011:68:1736-9 doi:10.2146/ajhp100597.

52 Tinjum BE, Getto L, Tiedemann J, et al. Female authorship in emergency medicine parallels women practicing academic emergency medicine. J Emerg Med 2011;41:723-7. doi:10.1016/j. jemermed.2010.04.014. 